\title{
"A expectativa não é muito boa não. É de desespero mesmo!" O impacto emocional na prática pedagógica dos professores em formação inicial
}

\author{
Izabelle Do Nascimento Pereira' \\ Luis Eugênio Martiny² \\ Pierre Normando Gomes-da-Silva ${ }^{3}$
}

\section{RESUMO}

O objetivo é compreender a relação do "viés de impacto" com a prática pedagógica dos professores em formação inicial (PFI), no Estágio Profissional Supervisionado em Educação Física (EPSEF-UFPB). Numa abordagem qualitativa e descritiva, a pesquisa realizou-se com estagiários matriculados na disciplina (EPSEF-UFPB) e utilizou para coleta: entrevistas semiestruturadas e protocolo de observação. A técnica de Análise de Conteúdo foi Categorial. Como resultados, nas categorias: emoções, aspectos motivadores e planejamento, os PFI criaram expectativas positivas e superestimaram o impacto emocional; suas ações pedagógicas foram influenciadas pelas emoções previstas; o planejamento foi flexibilizado e a motivação em estar no âmbito escolar diminuiu.

Palavras-chave: Emoções. Educação física. Estágio supervisionado

1 Graduada em Educação Física. Professora no Colégio Evolução. João Pessoa/Paraíba, Brasil.

E-mail: izabelle-np@hotmail.com

2 Mestre em Educação física. Professor efetivo do Instituto Federal de Educação, Ciência e Tecnologia do Rio Grande do Norte (IFRN). Natal/Rio Grande do Norte, Brasil. E-mail: luis_martiny@hotmail.com

3 Doutor em Educação. Professor associado de Educação Física da Universidade Federal da Paraíba (UFPB). João Pessoa/Paraíba, Brasil. E-mail: pierrenormandogomesdasilva@gmail.com 
julho/2018

"The expectation is not very good. It's despairate same!" The emotional impact of the pedagogical practice upon teachers in early formation

\begin{abstract}
The goal is to comprehend the link of the impact of the pedagogical practice upon teachers in early formation during the supervised professional internship in Physical Education (EPSEF-UFPB). In a qualitative and descriptive approach, the survey happened among students who were signed up to take the class (EPSEF-UFPB) and collected data by: semi-structured interviews and observation protocols. The content analysis technique was categorical. The results ranged within the following categories: emotions, motivating aspects and planning, The young teachers created positive expectations and overestimated the emotional impact. Their pedagogical actions were influenced by foreseen emotions; planning was made flexible and the excitement to be in the school decreased.
\end{abstract}

Keywords: Emotions. Physical education. Supervised internship

\title{
"La expectativa no es muy bueno en. Es igual a la desesperación!" El impacto emocional en la práctica pedagógica de los profesores en formación inicial
}

\section{RESUMEN}

El objetivo es comprender la relación del "sesgo de impacto" con la práctica pedagógica de profesores en formación inicial (PFI), en Práctica Profesional Supervisionada en Educación Física (EPSEF-UFPB). En un abordaje cualitativo y descriptivo, la pesquisa se realizó con becarios matriculados en la disciplina (EPSEF-UFPB) y utilizó para recolectar: entrevistas semiestructuradas y protocolo de observación. La técnica de Análisis de Contenido fue Categorial. Como resultados, en las categorías: emociones, aspectos motivadores y planificación, PFI crearon expectativas positivas y sobrestimaron el impacto emocional; acciones pedagógicas fueron influenciadas por emociones previstas; planificación fue flexibilizada y motivación de estar en ámbito escolar disminuye.

Palabras clave: Emociones. Educación física. Práctica supervisionada 


\section{INTRODUÇÃO}

O curso de licenciatura em Educação Física da Universidade Federal da Paraíba (UFPB) oferece do $5^{\circ}$ ao $7^{\circ}$ período o Estágio Profissional Supervisionado (EPS) como componente curricular. No primeiro estágio, que acontece no quinto período, os Professores em Formação Inicial (PFI) têm a possibilidade de desenvolver suas intervenções voltadas à Educação Infantil. Este estágio é caracterizado como sendo o primeiro momento em que os PFI assumem a regência de uma turma e que, portanto, conseguem estabelecer o contato com contexto escolar e com a prática pedagógica em si, ao menos dentro da graduação.

As disciplinas teóricas sem a aproximação com a prática, não são suficientes para uma formação completa, pois não possibilitam aos graduandos o encontro com as problemáticas da realidade, geradoras de experiências de ensino (MASSABNI, 2011). A teoria oportuniza a análise e o questionamento das ações na prática pedagógica dos docentes, sendo ela a que possui explicações teóricas não definitivas do que ocorre no cotidiano escolar (COELHO, 2011).

Planejar aula, escolher uma metodologia, alcançar objetivos, ser confrontado pelos alunos, estar apto para lidar com possíveis conflitos, são processos que fazem parte da atuação do PFI no decorrer do estágio. Processos esses, que durante a vivência, possibilitam mais do que experiências, mas também representam uma oportunidade de construções significativas na vida profissional (BEZERRA, et. al. 2012, p. 7).

Diante do momento de atuar dentro da escola fazendo a transposição didática de todo o conjunto de saberes docentes construídos no decorrer de alguns anos de curso, inúmeros sentimentos, emoções e inquietações tendem a ser despertados nos PFI. Dentro destas emoções sentidas e diversas interrogações frente a nova experiência, os PFI tendem a criar expectativas, boas e/ou ruins, antes de suas intervenções. Maturana (1998, p. 15), diz que "emoções são disposições corporais dinâmicas que definem os diferentes domínios de ação em que nos movemos".

Criamos inúmeras emoções com base no que pensamos sobre futuros momentos de nossas vidas, como vamos reagir, ou o que isso irá nos trazer, a fim de nos prepararmos para o que virá, muitas vezes, inclusive, superestimando o impacto que essas emoções nos causam. Van Dijk, Finkenauer e Polmann (2008), esclarecem que a tendência de prever e superestimar determinadas emoções relacionadas a um evento denomina-se "Viés de Impacto", ou seja, tudo aquilo que imaginamos sentir antes do fato realmente acontecer. Imaginamos com mais intensidade do que realmente é; p. ex., prevendo o que acontecerá nas suas intervenções, os PFI serão tomados de expectativas e a partir delas surgirão inúmeras emoções, positivas ou negativas.

Segundo Van Dijk, Finkenauer e Polmann (2008), há dois tipos de emoções: as previstas e as sentidas. Emoção prevista "é a intensidade e a duração da emoção que as pessoas antecipam sentir depois que eventos futuros tenham acontecido". E emoção sentida "é a intensidade e duração do sentimento que as pessoas realmente sentem depois 
do evento". Nesse sentido, destacamos que, emoções previstas se definem como sendo um estado de desconforto que é antecipado por algo que ainda não aconteceu. Contudo, as emoções sentidas podem ou não confirmar as emoções previstas.

A possibilidade de superestimar as emoções, sendo de forma positiva ou negativa, pode levar a um nível de frustração caso não seja o que realmente se espera. Assim, surgiu nossa questão problema: qual a relação do Viés de Impacto com a Prática Pedagógica dos PFI no EPS?

Portanto, nosso objetivo geral é compreender a relação do Viés de Impacto com a prática pedagógica dos PFI no EPS. E como objetivos específicos: identificar como se manifesta a expectativa dos $\mathrm{PFI}$ em relação à prática pedagógica; verificar se os $\mathrm{PFI}$ superestimam o impacto emocional no EPS; estabelecer a relação que este viés de Impacto tem com a prática pedagógica desses PFI.

No decorrer das atuações, os PFI constatarão se suas expectativas criadas acordaram ou não com a realidade de suas intervenções. Diante dos seguintes pressupostos: incertezas, desconfianças com relação à capacidade, da dúvida de estar realmente pronto para assumir o papel da docência, da inexperiência profissional no âmbito escolar, temos como hipótese que os PFI criam um viés negativo, superestimando a intensidade de suas emoções, resultando numa frustração diante da prática pedagógica, levando-os a uma ação sem sentido e prazer, podendo ocasionar o abandono da docência antes do término da formação.

Nesse sentido, o estudo torna-se pertinente por nos possibilitar entender que tipo de expectativa e quais emoções se desvelam no primeiro contato com a docência, nos permitindo compreender ainda, se esses fatores interferem na prática pedagógica.

\section{METODOLOGIA}

\section{Caracterização da pesquisa}

Esta pesquisa foi de caráter descritivo, por expor as características de determinada população (MORESI, 2003). Numa abordagem qualitativa, do tipo de campo, por constar de procedimento investigativo no espaço onde o fenômeno ocorre.

\section{Sujeitos}

A população deste estudo foi composta por estagiários (PFI), matriculados no componente curricular EPS I do curso de Licenciatura em Educação Física da Universidade Federal da Paraíba no ano/semestre 2012.2. Fizeram parte da pesquisa um grupo de quatro $\mathrm{PFI}$, sendo dois do sexo masculino e duas do sexo feminino. Todos eles atuaram no mesmo campo de intervenção do estágio, em um dos Centros de Referência em Educação Infantil (CREI) da Secretaria de Educação da Prefeitura Municipal de João Pessoa/PB. 
Para participar da pesquisa, os PFI não poderiam, anteriormente, ter estabelecido contato com a docência e deveriam realizar suas intervenções de estágio em instituições públicas. O grupo deveria ser coeducativo e desejar participar da pesquisa.

\section{Instrumentos e procedimentos para a coleta de dados}

Foram utilizados dois instrumentos para a coleta de dados, a saber: duas entrevistas semidiretivas ou semiestruturadas (BARDIN, 2011) e um protocolo de observação, baseado em Onofre (1995). A primeira entrevista foi realizada antes do primeiro contato dos PFI no CREI, continha dez questões abertas que pretendiam verificar as expectativas e sentimentos dos PFI com relação a suas atuações, sobre o conhecimento que eles possuíam a respeito do componente curricular EPS e da importância do estágio para sua formação.

A segunda entrevista foi composta por sete questões abertas, durante o período de intervenção, após a décima aula ministrada, sendo o momento em que os PFI encerraram a primeira unidade programática. Teve o intuito de verificar se as respostas dadas na primeira entrevista se confirmaram ou não durante a atuação dos PFI frente à experiência prática que o estágio proporcionou.

O protocolo de observação foi composto por três dimensões: instrução, organização e clima relacional. Onde, respectivamente, pudemos observar: o modo de o professor estabelecer o princípio de continuidade da sua aula; as estratégias utilizadas para conseguir a atenção dos alunos nos diversos momentos da aula e apreciar o ânimo do professor quando ministra as aulas.

No EPS I do curso de Educação Física da UFPB, os PFI ficaram três meses na escola fazendo intervenções pedagógicas e ministravam 20 aulas, para suas respectivas turmas. As turmas estavam divididas pela idade das crianças (dois, três, quatro e cinco anos) e possuíam uma média de 15 alunos cada, e eles ministravam três aulas semanais. Cada aula tinha duração de 45 minutos. As primeiras quatro aulas, os PFI atuaram juntos em todas as turmas. Após essas aulas, cada PFI ficou responsável por sua única turma.

Em virtude das limitações do estudo, optou-se por fazer um recorte da investigação, aplicando o pré-teste antes do início das intervenções e o segundo teste ao final da primeira unidade programática. Todavia, entende-se se fazer necessário a ampliação do estudo, para se ter a uma análise sobre as emoções sentidas ao final do EPS. Deixa-se a indicação de uma possível futura investigação, inclusive com a ampliação da amostra.

\section{Procedimento para a análise dos dados}

Para interpretação dos dados coletados foi utilizada a técnica de Análise de Conteúdo, especialmente a técnica Categorial, que consiste em classificar elementos em categorias, identificando o que cada um deles tem em comum com outros, para depois agrupá-los em suas semelhanças (BARDIN, 2011, p. 148). Nesta tarefa de classificação foi construído 
um mapa estruturante da análise dos dados, que nos possibilitou uma organização das unidades de contexto e de registro. As falas e observações (FeO) foram interpretadas e mapeadas, possibilitando a identificação das categorias temáticas: emoções, aspectos motivadores e planejamento.

Cada indivíduo que participou da coleta de dados assinou o Termo de Consentimento Livre e Esclarecido indicando que se disponibilizava a participar da pesquisa. O projeto foi aprovado pelo Comitê de Ética do CCS/UFPB com o número do protocolo: 031/13.

\section{RESULTADOS}

Foram encontradas três Unidades de Contexto (UC) ou categorias temáticas a partir das análises realizadas das duas entrevistas e das observações das intervenções dos PFI: Emoções, Aspectos motivadores e planejamentos. Para apresentar os resultados obtidos a partir das análises feitas, demonstramos no quadro 1, a seguir, um recorte do mapa estruturante dos dados coletados.

Quadro 1 - Categorias temáticas sobre o viés de impacto e sua relação com a prática pedagógica dos $\mathrm{PFI}$

\begin{tabular}{|c|c|c|c|}
\hline \multicolumn{4}{|c|}{ Elementos de análise } \\
\hline $\begin{array}{l}\text { Unidades de Contexto } \\
\text { (compreensão) } \\
\left(2^{\circ} \text { desdobramento }\right)\end{array}$ & \multicolumn{2}{|c|}{$\begin{array}{l}\text { Unidades de Registro } \\
\text { (significação) } \\
\left(3^{\circ} \text { desdobramento }\right)\end{array}$} & $\mathrm{FeO}$ \\
\hline \multirow{4}{*}{ Emoção } & \multirow{2}{*}{$\begin{array}{l}\text { Expectativa (imaginário/ } \\
\text { representação) }\end{array}$} & Positiva; & \\
\hline & & Negativa; & \\
\hline & \multirow{2}{*}{$\begin{array}{l}\text { Confronto com a } \\
\text { realidade (confrontação) }\end{array}$} & Confirmação; & \\
\hline & & Diferença; & \\
\hline \multirow{4}{*}{ Aspectos Motivadores } & \multirow{2}{*}{$\begin{array}{c}\text { Informações a respeito } \\
\text { do estágio (cultura } \\
\text { escolar) }\end{array}$} & Presente; & \\
\hline & & Ausente; & \\
\hline & \multirow[b]{2}{*}{ Trabalho em grupo } & $\begin{array}{c}\text { Conhecimento de si e do } \\
\text { outro; }\end{array}$ & \\
\hline & & $\begin{array}{c}\text { A importância da organização } \\
\text { didática pedagógica } \\
\text { construída coletivamente; }\end{array}$ & \\
\hline \multirow{2}{*}{ Planejamento } & \multirow{2}{*}{$\begin{array}{l}\text { Confirmação da ação } \\
\text { (sentimentos) }\end{array}$} & Permanência; & \\
\hline & & Abandono; & \\
\hline
\end{tabular}


A primeira UC observada nas FeO foi com relação às Emoções. A princípio, todos destacaram uma expectativa positiva em relação as suas primeiras intervenções no âmbito escolar: "Estou criando muita expectativa e espero que seja o que estou esperando. Sempre tive muita facilidade com criança. Minha expectativa está a mil. Eu quero muito que seja bem proveitoso" (PFI $1-1^{\circ}$ entrevista). Paralelamente, observamos que os PFI, com exceção do PFI 3, demonstraram em certos momentos, uma empolgação por cursarem a disciplina de estágio, ao mesmo tempo em que sentiam o desafio que estava por vir. A alegria da realização contrastava com a apreensão da vivência, o medo da responsabilidade e a dúvida da capacidade.

É um sentimento bom, mas ao mesmo tempo... um sentimento que dá um certo medo, sabe? Porque você trabalhar com criança... que estão sob sua responsabilidade, dá um certo medo (PFI $4-1^{\circ}$ entrevista).

O desejo de aprender, crescer profissionalmente, ajudar as crianças a se desenvolverem e vivenciar tudo que o EPS poderia proporcionar foi algo que ficou evidente nas falas de cada PFI. Contribuindo assim, para reforçar as expectativas positivas frente a tudo que esperavam experimentar na prática. Dentro desta categoria, a segunda entrevista confrontou as expectativas criadas antes das intervenções, a fim de descobrir se as emoções previstas pelos PFI se confirmaram na prática.

Após análise, constatamos que as expectativas não se confirmaram em apenas um dos PFI. A PFI 2 deixou bem claro seu pensamento sobre a emoção que sentiu frente a realidade vivida.

\begin{abstract}
Nada que eu tinha em mente, nada que eu esperava permaneceu. É um ambiente muito diferente. As dificuldades são enormes em tudo. Certo que eu não tinha experiência, mas tudo que achava que iria ser fácil... que se eu planejasse com aquela maior vontade eles iriam participar. Os de 2 anos não querem participar. Não me ajudam em nada. A expectativa não é muito boa não. É de desespero mesmo (PFI $2-2^{\circ}$ entrevista).
\end{abstract}

No encontro com a realidade, a PFI chega a afirmar que pensou em trancar o EPS I, devido às dificuldades que encontrou com sua turma, particularmente, com as inúmeras intervenções frustradas. A PFI relata que há um sentimento de inutilidade por não conseguir ministrar a aula como planejou:

Eu me senti, desculpe o termo... uma inútil. Quando comecei a dar minha aula, que eles não quiseram, foi àquela dificuldade. Perder 15 minutos. A metade da aula, para tirar eles daquele chão, pra vir fazer um círculo, pra cantar... Sinceramente... eu quase chorava (PFI $2-2^{\circ}$ entrevista).

Ao desejarem ter o controle da aula e de todos os alunos, a PFI foi tomada de emoções e sentimentos de ansiedade, tal como observado na pesquisa de Costa; Gomes-da-Silva 
e Schulze (2012), sobre a diferenciação da busca de controle da turma por profissionais em diferentes faixas etárias.

Nas observações das aulas, a PFI 2 demonstrou preocupação no contato com a turma, já que os alunos de 2 anos não estavam acostumados com a rotina do CREI. Na sua primeira ação pedagógica, ao chegar ao campo de intervenção, a PFI 2 declarou: "não sei o que fazer com minha turma, eles só choram". Em seguida, durante sua aula, ao ver o que acontecia naquele momento, ela disse: "pelo menos não estão chorando". Isso demonstra que, o fato de seus alunos não chorar mais, já era motivo de satisfação para ela.

O comportamento dos PFI frente à indisciplina dos alunos deixou evidente a preocupação em manter o controle da turma. Os quatro PFI geralmente ameaçavam acabar com a aula, ou retirar os alunos "bagunceiros" das atividades. Em momentos posteriores, ameaçavam dizendo que não voltariam mais para dar aula aos alunos, caso não se comportassem.

Nesses momentos de indisciplina, na dimensão clima relacional, os PFI se mostravam bastante irritados. Na tentativa de organizar a aula, geralmente faziam uso do apito. Sendo que, ao iniciarem suas intervenções do dia, os PFI lembravam aos alunos que o apito era usado para que todos ficassem em silêncio para ouvi-lo. Quando não funcionava, a estratégia era sentá-los no pátio e repreender toda a turma.

$\mathrm{O} \mathrm{PFI}$ 3, ao perceber que seus alunos não estavam se comportando, recolheu o material da aula e visivelmente chateado ameaçou ir embora. Sentando, avisou aos alunos que a aula tinha acabado, sendo necessária uma intervenção por parte da professora de sala, que os repreendeu e deu continuidade a aula.

Apesar de o PFI 4 relatar que suas expectativas em relação ao EPS foram confirmadas. Todavia, ficou evidente que, o encontro com a realidade o surpreendeu. Ele relatou que o fato de não conhecer a turma no início da sua prática pedagógica, deixou-o tenso e com dúvida se ele realmente era capaz de atuar naquele lugar. Declarou ainda que, por várias vezes, chegou ao CREI desanimado e com receio:

Já cheguei desanimado, quando a gente faz uma atividade num dia e essa atividade acaba e a gente vê que não conseguiu ser tão perfeito na aula, ou não conseguiu a dinâmica ideal, não conseguiu contagiar a turma. Você vai para próxima aula com receio [...] Você não sabe se a turma vai querer aquilo que planejou ou não. E assim acontece, você acaba levando pra outra aula (PFI $4-2^{\circ}$ entrevista).

As observações das intervenções confirmam o relato do PFI 4. Era perceptível o desânimo dos PFI, que consequentemente contagiava a turma. Às vezes por consequência de uma aula que não deu certo ou porque durante a aula os alunos não participavam. As professoras do CREI, em vários momentos, interviram nas aulas dos PFI, principalmente nas primeiras aulas, para que os alunos se animassem e participassem das atividades. A reação dos alunos com a animação das professoras era visivelmente positiva, elas conseguiam atrair as crianças para a aula com suas agitações e incentivos aos alunos.

Os PFI 1 e 3 relatam que suas expectativas foram confirmadas, que aquilo que visualizaram antes das intervenções realmente aconteceu. Os PFI declararam estarem satisfeitos 
com suas vivencias: "O estágio é o que imaginei: um pouco complicado, pouco não, é muito né? Mas que dá pra ser levado. Sinto prazer dar aulas pra eles" (PFI $3-2^{\circ}$ entrevista).

A segunda UC, ou categoria observada, está relacionada aos Aspectos Motivadores da Prática Pedagógica. Essa categoria nos aponta aspectos determinantes para a expectativa positiva criada antes das intervenções. Todos os PFI relataram que só ouviram, antes do primeiro contato com o CREI, comentários positivos a respeito do EPS. Esses comentários foram feitos por alunos do curso que já passaram pela disciplina ou pelo próprio professor de EPS. O PFI 3, na primeira entrevista afirmava: "Eu já me imagino lá dando aula. Toda vez que eles falam em uma atividade que eles fizeram, me imagino fazendo. Acho muito bom".

O fato dessas informações se confirmarem na prática para os PFI 1 e 3, foi determinante para continuarem motivados durante suas intervenções. Destacamos, inclusive, que o resultado de suas intervenções geraram novos aspectos motivadores, que possibilitaram um maior respaldo dos comentários feitos. Para a PFI 1, o fato de seus alunos se disponibilizarem a fazer tudo que ela propunha na aula era motivador e trazia satisfação: "Depois da prática eu sempre saí com um sentimento bom, positivo, porque a gente vê que não tem rejeição, o que a gente propõe eles querem fazer" ( $2^{\circ}$ entrevista).

Já para os PFI 2 e 4, a ausência de confirmação das informações obtidas antes do contato com a docência gerou uma desmotivação, causando desânimo e frustração em ambos: "O estágio não tá sendo nada do que eu imaginei. Tá sendo uma frustração muito grande a minha realidade em sala de aula" (PFI $2-2^{\circ}$ entrevista).

Outro aspecto motivador encontrado nas entrevistas dos quatro PFI foi a oportunidade de se trabalhar em grupo. Os PFI se mostraram satisfeitos e confiantes por participarem do mesmo grupo, já que eram bastante íntimos e demonstraram já saber lidar uns com os outros. Os quatro relataram a afinidade: "Estou no $5^{\circ}$ período e desde o $1^{\circ}$ que é o mesmo grupo, tem a linha de pensamento próxima e um sempre dá ideia para o outro. É um grupo que se completa" (PFI $2-1^{\circ}$ entrevista).

A terceira UC encontrada a partir das análises está relacionada ao Planejamento na Prática Pedagógica dos PFI. A primeira entrevista deixa claro que eles antes de terem contato com o campo de intervenção já se preocupavam ou pensavam em planejar suas aulas, seus métodos e objetivos que poderiam propor para suas respectivas turmas: "Para crianças pequenas estou me preparando, imaginando como eu vou trabalhar as atividades, até pelo depoimento que a outra turma nos deu" (PFI $3-1^{\circ}$ entrevista).

Depois da experiência de ministrarem as quatro primeiras aulas juntos, os PFI foram incisivos em suas falas ao relatar que planejar em grupo facilitava o processo.

O planejamento era todos fazendo, todos buscando, todos tentando melhorar e lá, no momento, todos fazendo as atividades, demonstrando e aplicando. E hoje não, eu que sou a professora, eu que tenho que me impor, eu que digo o que fazer e o que não fazer, a diferença é essa (PFI $2-2^{\circ}$ entrevista).

Apesar de se prepararem para o que a prática pedagógica exigiria deles, os PFI perceberam dificuldades em planejar e executar. Sendo visível que o confronto com a realidade não foi condizente com o que se pensava a respeito dela. 
Eu pensei que fosse mais fácil por ter muitas atividades, mas acho que pelo leque ser tão grande se torna difícil trabalhar. Porque a gente tem que trabalhar com o que elas gostam, até acertar. Saber o que elas gostam, a dificuldade é essa (PFI $4-2^{\circ}$ entrevista).

A PFI 1 sentiu receios e dúvidas sobre as escolhas das atividades. Possuía incerteza sobre se de fato, o que planejou iria ser bem aceito pelos alunos. Ou se teria que mudar o que planejou: "Em alguns momentos vem a questão da dúvida: se vai dar certo ou não; se a gente leva uma atividade e vê que não funciona, fica aquela indecisão, faço outra coisa ou não" (PFI $1-2^{\circ}$ entrevista).

A PFI 2 demonstrou frustração por não conseguir por em prática o que planejou. Relatou seu esforço e dedicação à turma, mas descreveu seu fracasso e tristeza: "Eu faço minhas aulas, pesquiso, essa atividade vai dar certo. Mas todas as atividades que imponho lá eles não querem. Eu pego na mão, mas eles sempre... É aquela rejeição comigo, e até com os meninos" [os outros PFI] ( $2^{\circ}$ entrevista).

Ao observar as aulas, ficava evidente o desejo deles de ver o que se planejou dar certo. Porém, o medo da reação dos alunos, frente a uma nova atividade, impulsionava os PFI a repetirem as atividades que deram certo no início das intervenções. Ao repetirem várias vezes certas atividades, em dias diferentes, deixaram os alunos desmotivados a participarem das aulas. Em uma determinada aula do PFI 4, os alunos, ao perceberem que a atividade era a mesma que já tinham vivido diversas vezes, reclamaram que estavam cansados e começaram a sentar, um a um. Assim, os PFI terminavam quebrando o princípio da progressividade em suas aulas, devido ao medo de planejar algo que não seria bem aceito.

Frente a toda dificuldade encontrada e a toda decepção que sentiu por confrontar a realidade com suas expectativas e com aquilo que imaginava ser o EPS, a PFI 2 relata que pensou em um determinado momento de sua prática pedagógica em trancar o estágio,

diz ela: "Eu parei pra pensar, trancar esse período com a creche, porque tô tendo muita dificuldade com a turma [...], mas depois das 10 aulas dadas, não poderia perder isso que eu trabalhei" (PFI $2-2^{\circ}$ entrevista).

\section{DISCUSSÃO}

A partir das três UC, observamos que tipo de expectativas são criadas e quais os desdobramentos que interferem de maneira positiva e/ou negativa na prática pedagógica dos PFI. É importante esclarecer que cada PFI adotou para orientar suas intervenções a teoria pedagógica da Psicocinética (LE BOULCH, 2008).

Vimos que as expectativas positivas formadas antes das intervenções, por cada PFI, modelam o comportamento, ou as ações iniciais, que logo vão sofrendo modificações com base nas novas percepções da realidade vivenciada, e não mais no "viés de impacto". As ações de planejamento, relação professor-aluno e execução das aulas são modificadas a partir da realidade encontrada. Neste sentido, a motivação pode passar a não ser a mesma, 
assim como o desejo de estar no âmbito escolar pode ficar diminuído e a animação em dar aula quase deixar de existir.

As atitudes como planejar aulas com atividades diferentes, chegar alegres ao CREI e interagir espontaneamente com os alunos, durante as intervenções, foram sendo modificadas à medida que o resultado do contato com a realidade foi sendo percebido.

Apenas queremos sublinhar que os humanos formam em sua mente algo que podemos chamar representações ou modelos da realidade, que são muito adequados para explicar o que ocorre e que lhes servem para agir e para antecipar o que irá acontecer (DELVAL, 2010, p. 121).

A prática pedagógica é construída a partir dessas representações sobre a aula, sobre a turma e sobre o EPS. Quando o PFI não sai satisfeito com o resultado da sua prática, criando emoções negativas, ele percebe que aquela realidade não condiz com suas previsões ou representações, que são interpretações da realidade. "A relação com o real nunca é direta; é sempre mediada por categorias históricas, subjetivamente constituídas" (SPINK, 1993, p. 304).

Ao preverem como seria o estágio e suas intervenções e, ao serem confrontados com a realidade vivida, a ideia do "estágio perfeito", em que os PFI se imaginam tendo o controle total da aula, do tempo, do comportamento dos alunos, do espaço e da execução do planejamento, vai se desfazendo. Quando se esforçam no planejamento e percebem que os alunos não quiseram participar, os PFI se veem perdidos sem saber como modificar esse comportamento.

O processo de construção identitária dos PFI no espaço tempo do Estágio Supervisionado, tem início com suas próprias expectativas em torno do papel que será assumido. Ao relatarem suas expectativas, os PFI revelam imagens pré-concebidas, em torno da realidade a ser encontrada (BEZERRA, 2012, p. 69).

Por consequência das previsões não assertivas, surgem emoções negativas: tristeza, frustração, desgosto, decepção e até mesmo o desejo de abandonar o EPS. Porém, quando a expectativa é correspondida, os PFI se sentem mais confortáveis e motivados para as próximas ações pedagógicas no campo de intervenção, o que acaba gerando sentimentos positivos como: alegria, prazer, satisfação e uma autoafirmação de suas práticas.

Apesar dos fatos negativos, é necessário vivenciar todo o processo que o estágio oferece, desde o conhecimento da realidade da profissão ao conhecimento de si próprio, dos saberes adquiridos e de suas limitações. Martiny e Gomes-da-Silva (2011) evidenciam a necessidade dos PFI possuírem uma visão crítica da sociedade, que esteja inserido de forma que no ambiente escolar possa perceber a pluralidade e a dinâmica deste ambiente, com seus conflitos e significados.

Observamos também que dois sujeitos da pesquisa, PFI 2 e PFI 4, superestimaram o impacto de suas emoções. Ao não obterem a confirmação de suas expectativas positivas, 
julho/2018

acabaram por dar um valor excessivo a elas, de modo que a intensidade das emoções negativas que surgiram foram maior do que as esperadas.

Várias pesquisas sugerem, entretanto, que as pessoas são incorretas na previsão das suas emoções para decisões futuras ou eventos. Eles comumente superestimam a intensidade e duração de suas emoções para uma larga variedade de eventos focais, quer dizer, elas demonstram um viés de impacto (VAN DIJK; FINKENAUER; POLMANN, 2008).

De acordo com a segunda UC, Aspectos Motivadores, obtivemos dois desdobramentos: as informações a respeito do estágio e o trabalho em grupo.

A troca de informações acerca de como o EPS funciona, a partir dos comentários dos PFI, que já passaram pelo estágio, ou do próprio professor, acabam proporcionando mais confiança e expectativa do que a experiência é capaz de oferecer. Essa representação adquirida influencia as atitudes iniciais dos PFI, pois quando o envolvido tem pouca experiência e pouco conhecimento de determinada questão, as mensagens ditas por fontes especializadas são capazes de produzir mudança de atitudes (MICHENER; DELAMATER; MYERS, 2005). Quando essas representações se confirmaram, tivemos os PFI satisfeitos e seguros em suas práticas, como foi o caso da PFI 1 e do PFI 3.

O trabalho em equipe, outro aspecto motivador, é mais um componente que possibilita aos PFI uma segurança em suas ações pedagógicas. É importante ressaltar que a proposta de EPS era baseada no tripé: Ação - Reflexão Crítica -Nova Ação (GOMES-DA-SILVA, 2009), apostando na reflexão do vivido como norteadora de uma prática pedagógica consciente e criativa, porque mais singularizada. Tendo em vista que essa proposição triádica, que valoriza a singularização do professor, em seu fazer pedagógico coletivo, está sistematizada na Pedagogia da Corporeidade (GOMES-DA-SILVA, 2016). Assim, cada PFI, além de ajudar o outro, tem a oportunidade de observar as intervenções dos colegas e refletir sobre suas próprias, possibilitando o conhecimento de si e do outro. Ao conhecer o outro através das observações da prática pedagógica, o PFI passa a conhecer a si mesmo, analisando suas próprias ações e traçando alguns propósitos para uma ação futura (MARTINY, 2011, p. 135). Os PFI ao relatarem que planejar e ministrar a aula em conjunto facilitava a prática pedagógica, demonstram que a organização didático-pedagógica, construída coletivamente, gera segurança teórico-prático.

Na terceira e última UC encontrada na análise, Planejamento, foram encontradas as maiores dificuldades dos PFI. Com a confirmação ou não das emoções, cada PFI teve seus momentos de desânimos e incertezas ao planejarem. Quais os objetivos que queriam atingir? Quais atividades adequadas? Que tipo de comportamento esperar dos alunos? Com estes questionamentos para a próxima aula, a apreensão e tensão ficaram visíveis nas observações das aulas. Marcello (2013), em sua pesquisa, aponta que planejar aula experimentando sensações de ansiedade, medo, insegurança, pessimismo, raiva, cansaço e falta de motivação, é um estado que limita os pensamentos e deixa o professor sem recursos para ministrar uma aula de qualidade. 
Nas aulas iniciais cada PFI percebeu a preferência dos seus alunos. De modo que, ao propor novas práticas e perceber desinteresse, os PFI, quase sempre, retornavam para suas as práticas que seus alunos gostavam. Daí a mudança de planejamento na hora da aula tornar-se constante. No medo de provocar o desinteresse e evasão, os PFI cediam aos desejos de seus alunos.

A PFI 2, em determinado momento, pensou em desistir do estágio, e relatou que não o fez por não querer abrir mão do trabalho que já tinha feito. Os estudos de Franco (2008) também nos apontam para esta confrontação, que dependendo do modo de lidar com elas, pode se tornar uma circunstância capaz de informar e transformar o sujeito, ou oprimir, distorcer e congelar. A autora ainda revela que, neste contexto, a prática é sempre mais do que aquilo que se supõe à primeira vista e sempre menos inteligível do que seria necessário considerar.

São inúmeras as influências que as emoções trazem para a prática pedagógica dos PFI, exigindo destes o equilíbrio emocional, indispensável na atuação profissional. A inteligência emocional é um "conjunto de habilidades relacionadas à percepção, expressão e regulação das emoções em si mesmo e nos outros, e à utilização das emoções para motivar, planejar e atingir objetivos na vida" (SALOVEY; MAYER apud BUENO et. al., 2006). O equilíbrio emocional, assim, torna-se um desafio não tão fácil de ser conquistado, já que diariamente, como afirma Guebur; Poletto e Vieira (2007, p. 86), o sujeito defronta-se com situações novas, sendo necessário fazer uso das emoções de forma inteligente, orientando "o comportamento e o raciocínio no intuito de obter melhores resultados".

Na figura 1 a seguir, explicitamos de maneira visual todo desdobramento encontrado no decorrer da discussão. As informações sobre o estágio e a imagem interna que cada PFI construiu sobre o que iria acontecer, gerou uma representação da realidade, um "viés de impacto" e esse viés modelou o comportamento inicial dos PFI. Esse comportamento inicial corresponde ao planejamento e execução das primeiras ações pedagógicas, ânimo e motivação no campo de intervenção e relação professor-aluno.

Após o comportamento inicial, os PFI são confrontados com a realidade da cultura escolar, a não execução do planejamento como se esperava e a indisciplina dos alunos. Esse confronto causa nos PFI um novo estado emocional, só que agora não mais com emoções previstas, mas com as emoções sentidas de fato. Maturana (1998, p. 92) nos diz que, "se queremos entender as ações humanas não temos que observar o movimento ou o ato como uma operação particular, mas a emoção que o possibilita". 


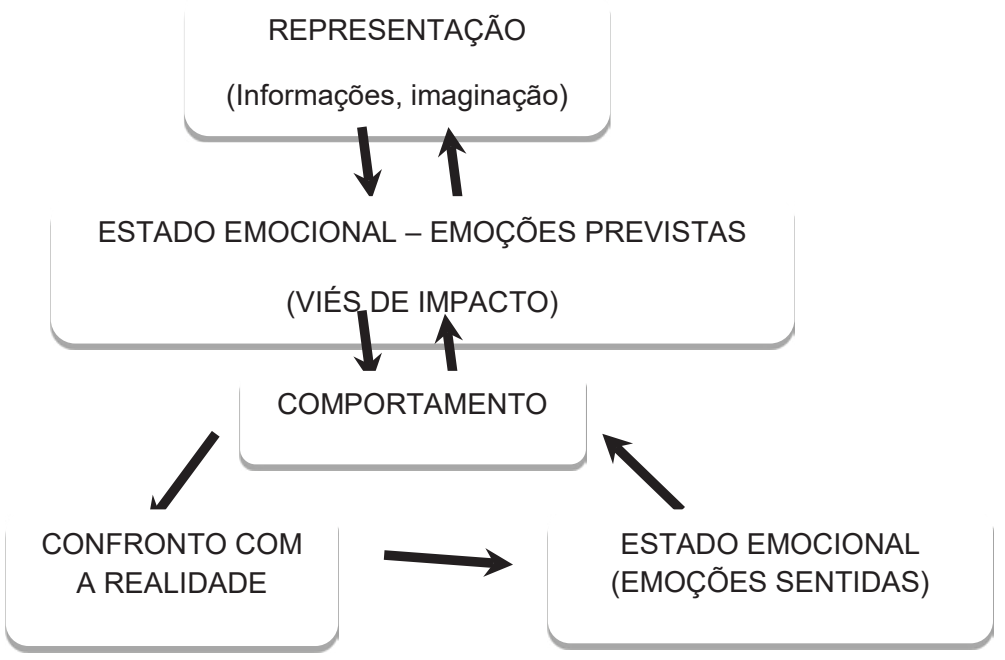

Figura 1 - Desdobramento do caminho dos PFI sobre a prática pedagógica

\section{CONCLUSÃO}

O novo estado emocional proporciona um novo comportamento, agora não mais por consequência da representação e sim pelo confronto com a realidade. Esse novo comportamento consiste em: planejar as aulas, em confronto com a realidade, o desânimo devido a baixa produtividade, que é potencializada com a dúvida de ser capaz ou não de fazer as coisas acontecerem. Este novo comportamento dá lugar a novas emoções, portanto, a um novo "viés de impacto".

As expectativas positivas por parte de todos os PFI e a superestimação do impacto emocional confirmaram a relação existente entre viés de impacto e prática pedagógica. Esta evidência aponta que as atitudes dos PFI baseiam-se nas emoções previstas e que o caminho percorrido nas intervenções é reflexo desta relação.

Os resultados também denotam que, as reflexões feitas nos momentos em que os PFI se juntavam para discutir sobre as aulas, diminuem o "viés de impacto", porque a partir da reflexão eles percebem que a realidade encontrada não é resultado de suas ações, é algo que faz parte do todo.

A falta de vivências docentes anteriores a esta nos faz questionar se a experiência ou o contato com a docência, caso os PFI tivessem, afetaria ou modificaria este "viés de impacto". Ressalta-se, portanto, a ideia do estágio não ser marcado como a única e muitas vezes a primeira experiência de docência, ou seja, o primeiro contato com a regência e por conseguinte, com a realidade escolar. 


\section{REFERÊNCIAS}

BARDIN, Laurence. Análise de Conteúdo. São Paulo: Edições 70, 2011.

BEZERRA, Brígida Batista. Formação profissional em educação física. 2012. Dissertação (Mestrado em Educação Física) - Programa Associado de Pós-Graduação em Educação Física/ Universidade de Pernambuco-Universidade Federal da Paraíba, João Pessoa, 2012.

BEZERRA, Brígida Batista. et. al. 10 Anos de estágio supervisionado no curso de educação física da Universidade Federal da Paraíba (UFPB). Coleção Pesquisa em Educação Física. v. 11, n.1, 2012.

COELHO, Simony Ricci. Representações sociais do estágio supervisionado no curso de letras de uma Universidade na baixada Fluminense. 2011. 97f. Dissertação (Mestrado em Letras e Ciências Humanas) - universidade do Grande Rio - UNIGRANRIO, Rio de Janeiro. 2011.

COSTA, Sandra Barbosa; GOMES-DA-SILVA, Pierre Normando; SCHULZE, G.B. O tempo pedagógico do professor de educação física escolar. In: CATTUZZO, M.T; CAMINHA, Iraquitan Oliveira. (orgs.) Fazer e pensar ciência em educação física - Livro 1. João Pessoa: Ed. Univ. da UFPB, 2012, p. 219-238.

DELVAL. Juan. Aprender investigando. In: BECKER, Fernando; MARQUES, Tânia Beatriz Iwaszko. (Orgs). Ser professor é ser pesquisador. Porto Alegre: Mediação, 2010.

FRANCO, Maria Amélia Santoro. Entre a lógica da formação e a lógica das práticas: a mediação dos saberes pedagógicos. Educ. Pesqui. v. 34 n.1. São Paulo Jan./Apr. 2008.

GOMES-DA-SIIVA, Pierre Normando. Educação Física pela pedagogia da corporeidade: um convite ao brincar. Curitiba, 2016.

GOMES-DA-SILVA, Pierre Normando. Prática de ensino em Educação Física. In: HERMIDA, Jorge Fernando. (Org). Educação Física: conhecimento e saber escolar. João Pessoa, PB: Editora Universitária da UFPB, 2009.

GUEBUR, Andréa Zocateli; POLETTO, Cleusa Aparecida; VIEIRA, Daicy Maria Sipoly. Inteligência emocional no trabalho. Revista Intersaberes. Curitiba, ano 2, n. 3, p. 71 - 96, jan/jun 2007.

LE BOULCH, Jean. O corpo na escola no século XX. SP: Phorte, 2008

MARCELLO, Ricardo Luis. Lidando com as emoções I. Disponível em: (http://www. portalcmc.com.br/saladeaula02.htm). Acesso em 06 de Abril 2013.

MARTINY, Luis Eugênio. A transposição didática na Educação Física Escolar. 2011. 173f. Dissertação (Mestrado em Educação Física) - Programa Associado de Pós-Graduação em Educação Física/ Universidade de Pernambuco e universidade Federal da Paraíba, João Pessoa. 2011.

MARTINY, Luis Eugênio; GOMES-DA-SILVA, Pierre Normando. O que eu transformaria? Muita coisa!: Os saberes e os não saberes docentes presentes no estágio supervisionado em Educação Física. Rev. educ. fis. UEM. v. 21, n. 4. Maringá Oct./Dec. 2011.

MASSABNI, Vânia Galindo. Os conflitos de licenciados e o desenvolvimento profissional docente. Educ. Pesqui. v. 37, n. 4. São Paulo. Dec. 2011. 
julho/2018

MATURANA, Romesín Humberto. Emoções e linguagem na educação e na política.

Tradução José Fernando Campos Fortes - Belo Horizonte: Ed. UFMG, 1998.

MICHENER, H. Andrew; DELAMATER, John D.; MYERS, Daniel J. Psicologia Social. São Paulo: Thomson learning, 2005.

MORESI, Eduardo. Metodologia da pesquisa. Brasília: Ed. da UCB, 2003.

ONOFRE, Marcos. Prioridades de formação didática em Educação Física. Boletim da Sociedade Portuguesa de Educação Física, n. 12, p. 75-97, inverno/primavera, 1995. SPINK, Mary Jane Paris. O conceito de representação social na abordagem psicossocial. Cad. Saúde Públ. Rio de Janeiro, v.9, n.3, p.300-308, jul/sep, 1993.

VAN DIJK, Wilco; FINKENAUER, Catrin; POLMANN, Monique. The Misprediction of emotions in track athletics: Is experience the teatcher of all things? Basic and applied social psychology, v. 30, p.369-376, 2008.

Recebido em: Abril/2017 Aprovado em: Outubro/2017 